\title{
AN ASSESSMENT OF COLLEGE RECRUITMENT LITERATURE: Does the High School Senior Understand it?
}

\author{
Russell H. Johnson and David W. Chapman, The University of \\ Michigan
}

This study investigated the reading difficulty level of college recruitment literature and the ability of college-bound high-school students to understand the terminology frequently used in college admissions. The reading difficulty of the forty-two catalogs and analyzed was at a level appropriate to an advanced college student or college graduate. Moreover, high-school students had considerable difficulty identifying the correct use of terms commonly found in sections of college catalogs.

Key words: admissions; college choice; readability; student consumerism

The decision to attend an institution of postsecondary education and the choice of the particular institution to attend are two of the most important decisions students make during their schooling. These choices are no better than the information on which they are based. In the last few years, that information has received a great deal of criticism from both government and the larger public (Stark, 1977; Chapman, 1979). Institutions are under considerable pressure to provide more clear, accurate and complete information to prospective students (Stark, 1977; Stark and Terenzini, 1978). For example, the Education Amendments of 1976 contain "Student Consumer Information Provisions" designed to ensure that accurate and complete information is provided to students about many aspects of the college experience.

Most of the previous research and literature advocating improved recruitment literature has been concerned either with particular content that should be conveyed to students or with the accuracy of the con-

Address reprint requests to Dr. David Chapman, Project CHOICE, 2001 School of Education, The University of Michigan, Ann Arbor, MI 48109. 
tent that is presented. In many institutions, however, the problem may not be the inaccuracy or incompleteness of catalog information. Rather, the information may be presented in ways that are confusing or not well-understood. Yet the appropriateness of the reading level and terminology employed in college catalogs has received little, if any, research attention. While problems in reading level and vocabulary can cause confusion which-in turn-can contribute to inaccurate college expectations among the applicants, problems with the reading level are easily within the capacity of the institution to remedy.

The present study investigated the reading level difficulty of college recruitment literature and the ability of college-bound high-school students to understand the terminology frequently used in college admissions.

\section{METHODOLOGY Reading Difficulty}

During Fall 1978, forty-two catalogs were collected from a stratified random sample of 44 colleges and universities in the United States. Institutions were stratified by four categories following the Carnegie Commission (1973) classification scheme. The categories used were: (1) research universities, (2) comprehensive colleges and universities, (3) liberal arts colleges, and (4) two-year colleges and institutes. The materials from two institutions were subsequently dropped from the study because they had been commercially developed by marketing firms and would not be described as a college catalogue. Thus, fortytwo catalogues were actually included in the analysis.

A passage of at least 100 words was selected from each of three sections of the catalogue: (1) academic policies and procedures, (2) admission information, and (3) financial aid information. Within each section, passages were selected randomly.

The reading difficulty of each passage was computed using the Flesch Reading Ease Formula (Flesch, 1951; Smith and King, 1977). This formula is based on the number of words per sentence and the number of syllables per 100 words. The Flesch formula was selected because of its reliability and validity at both high school and college levels and because of its ease of application (Smith and King, 1977; Gilliland, 1972, Klare, 1963). It is one of the most widely known and frequently used of all readability formulas (Gilliland, 1972). Klare (1963) provides a good review of the validation studies involving the Flesch formula. Among other studies, he reports correlations between the Flesch, Olemann, and Gray-Leary Reading Tests and the Dale-Chall readability formula of $.82, .55$, and .98 respectively. Klare (1963) also reports studies showing correlations with expert judgment ranging from 
.61 to .84 . The Flesch formula can be easily applied without a computer. A guide for interpreting Flesch scores is presented in Table 1. (Note that the lower the reading ease score, the more difficult the reading level of the material.)

\section{Admissions Terminology}

During the Fall semester of 1978,206 high school senior students completed the College Terminology Quiz (CTQ) and a short demographic questionnaire.

The high school students completing the questionnaire were from three high schools which were selected because the teachers were willing to participate in the study. In all cases, the questionnaire was administered by a teacher or the high school guidance counselor. While representativeness of the sample cannot be ascertained, the schools were distributed across urban, suburban, and rural settings and across three different states. Table 2 reports the distribution of students by their plans to attend or not attend college, by whether or not their parents attended college, and by the type of college they expect to attend.

For each quiz item on the CTQ, students were asked to identify the one sentence from among four sentences demonstrating correct usage of the term (examples of items are presented in Figure 1).

The CTQ was developed as a criterion-referenced test. A student's score did not depend on how other individuals performed, but, rather, on the proportion of items that the student could correctly answer (Gray, 1978; Millman, 1973; Gronlund, 1973). Terms were selected based on high frequency of use in admissions materials, and correct answers were all sentences drawn directly from college catalogs. The items were reviewed for relevance, clarity, and appropriateness by a panel of three researchers with experience in college admissions. Eighteen items were included in the final form of the CTQ.

Identifying an appropriate standard for student performance posed some difficulty. There is no empirical evidence to suggest the level of knowledge of admissions terminology that corresponds to successful adjustment to college. The decision, then, was arbitrary. Ideally, college-bound students should be familiar with all the terminology presented. This level is, however, unrealistic and probably unnecessary. In this study, a standard of $80 \%$ was adopted, following the recommendations of Gronlund (1973) and Block (1971).

\section{Analysis}

Reading difficulty scores for each of the catalog sections and for the total catalog were compared to national norms (Smith and King, 1977). 


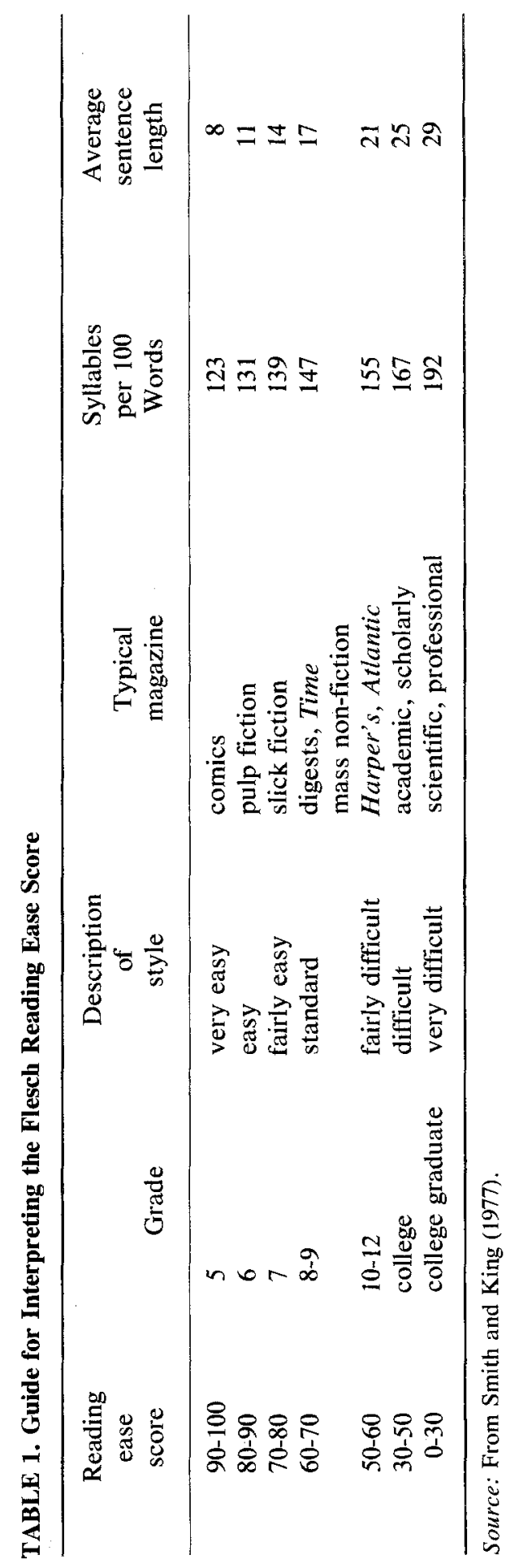


TABLE 2. Reading Ease Scores and Level of Difficulty: Means, Standard Deviations, and Grade Equivalents for Catalogs Analyzed

\begin{tabular}{|c|c|c|c|c|}
\hline & \multicolumn{3}{|c|}{ Reading Test Score } & \multirow{2}{*}{$\begin{array}{c}\text { Grade }^{a} \\
\text { equivalent }\end{array}$} \\
\hline & $N$ & $X$ & $\mathrm{SD}$ & \\
\hline Total catalogs & 42 & 33.5 & 11.2 & $\begin{array}{l}\text { Upper college } \\
\text { (very difficult) }\end{array}$ \\
\hline \multicolumn{5}{|c|}{ Total catalogs: specific sections } \\
\hline Academic policy & 42 & 37.6 & 16.5 & $\begin{array}{l}\text { Upper college } \\
\text { (very difficult) }\end{array}$ \\
\hline Admissions & 42 & 31.8 & 13.5 & $\begin{array}{l}\text { Upper college } \\
\text { (very difficult) }\end{array}$ \\
\hline Financial aid & 42 & 33.7 & 15.0 & $\begin{array}{l}\text { Upper college } \\
\text { (very difficult) }\end{array}$ \\
\hline \multicolumn{5}{|c|}{ Catalogs by Type of Institution } \\
\hline $\begin{array}{l}\text { 2-Year colleges and } \\
\text { institutes }\end{array}$ & 10 & 33.6 & 6.1 & $\begin{array}{l}\text { Upper college } \\
\text { (very difficult) }\end{array}$ \\
\hline Liberal-arts college & 10 & 40.7 & 5.4 & $\begin{array}{l}\text { College level } \\
\text { (difficult) }\end{array}$ \\
\hline $\begin{array}{l}\text { Comprehensive colleges } \\
\text { and universities }\end{array}$ & 11 & 35.1 & 11.9 & $\begin{array}{l}\text { Upper college } \\
\text { (very difficult) }\end{array}$ \\
\hline Research universities & 11 & 25.2 & 13.3 & $\begin{array}{l}\text { College graduate } \\
\text { (very difficult) }\end{array}$ \\
\hline
\end{tabular}

aFrom Smith and King (1977). Reading ease score intervals corresponding to grade equivalents are reported in Table 1.

An analysis of variance was computed to test the significance of differences between types of institutions. When warranted, post hoc comparisons were computed using the Scheffe Test.

Student scores on the terminology test were reported as total number of items correct. Analysis of variance was used to determine if students differing in their demographic characteristics significantly differed in their CTQ scores. Where appropriate, post hoc comparisons were computed using the Scheffe Test.

\section{RESULTS \\ Reading Difficulty}

Mean reading ease scores by catalogue, section of catalogue, and by type of institution are reported in Table 2. The reading difficulty of the 42 catalogues analyzed was rated at difficult to very difficult (Table 2). The average reading level, then, was appropriate to an advanced col- 
FIGURE 1. Selected Examples from the College Terminology Quiz

\section{Directions}

This quiz is designed to measure your familiarity with the words often used in describing colleges and college programs. Your scores on this test will not influence your grade in this class in any way. However, it is important that you answer all the questions and do the best you can.

For each item,

CHECK THE SENTENCE IN WHICH THE UNDERLINED WORD(S) IS MOST APPROPRIATELY USED

8. A A Y You may transfer credit from college courses you may have $a u^{-}$ dited during high school.

B. If you audit the course, you will not receive academic credit.

C. All graduating college seniors are expected to audit courses.

D. All courses that are audited are accepted for transfer credit.

9. A. The college is accredited by parents who are dissatisfied.

B. The college is accredited because of failing to comply with state regulations.

C. The college is accredited by the North Central Association of Colleges and Secondary Schools.

D. The college is accredited unanimously by all students that attend.

10.

A. Only students at private colleges and universities have to pay $t u$ ition.

B. Graduates of the college are responsible for paying tuition.

C. Full time college students are responsible for paying tuition.

D. While going to public high schools, students are responsible for paying tuition.

Note: A correct answer to an item did not necessarily describe all correct uses of the term being tested. However, of the four alternatives presented in each item, only one was correct.

lege student or college graduate (Smith and King, 1977). No significant differences in reading difficulty among the three sections of the catalogs were observed. Differences in the type of information being presented did not appear to result in differences in reading difficulty. The reading difficulty of catalogs, however, did differ significantly by institutional type (Table 3 ). Research university catalogues were significantly more difficult than those of the liberal arts colleges included in the sample. Relative to national norms (Smith and King, 1977), catalogues from all types of institutions are written at a level too difficult for their clientele. However, liberal arts college catalogs appear to be most congruent 
TABLE 3. Analysis of Variance of Reading Ease Score by Type of Institution.

\begin{tabular}{|c|c|c|c|c|c|}
\hline Source & d.f. & $\begin{array}{l}\text { Sum of } \\
\text { squares }\end{array}$ & Mean square & $F$ ratio & $F$ prob. \\
\hline Between groups & 3 & 1309.30 & 436.44 & 4.35 & .009 \\
\hline Within groups & 38 & 3812.31 & 100.32 & & \\
\hline Total & 41 & 5121.60 & & & \\
\hline
\end{tabular}

with the reading ability of their clientele. Catalogues from major research universities were significantly more difficult than those of the liberal arts colleges included in the sample. To the degree that a catalogue at overly difficult reading level contributes to an incomplete or inaccurate understanding of the institution, students entering research universities may experience the greatest trouble in clearly understanding what they should expect at the institution.

\section{Admissions Terminology}

Student scores on the CTQ, as a total group, and separated by differing student characteristics, are reported in Table 4. The highest possible score was 18 . As Table 4 shows, the average student score was only 10.12 correct items ( 56.2 percent), well below the 80 percent standard. The average score suggests that students had considerable diffi-

TABLE 4. Student Scores on the College Terminology Quiz

\begin{tabular}{lccc}
\hline Group & $\begin{array}{c}\text { No. of } \\
\text { respondents }\end{array}$ & Mean & S.D. \\
\hline $\begin{array}{l}\text { All students combined } \\
\text { Students planning to attend }\end{array}$ & 206 & 10.12 & 3.5 \\
$\quad$ college & 168 & 10.60 & 3.3 \\
$\begin{array}{l}\text { Students not planning to attend } \\
\quad \text { college }\end{array}$ & 33 & 8.20 & 3.4 \\
$\begin{array}{l}\text { Parents did attend college } \\
\text { Parents did not attend college }\end{array}$ & 125 & 10.74 & 3.38 \\
Student expected to attend: & 74 & 9.28 & 3.28 \\
$\quad$ community college & & & \\
$\quad \begin{array}{l}\text { 4-year private college } \\
\text { 4-year public college }\end{array}$ & 27 & 9.89 & 3.48 \\
$\quad \begin{array}{l}\text { university } \\
\text { undecided }\end{array}$ & 30 & 12.17 & 2.67 \\
& 32 & 10.41 & 2.88 \\
& 45 & 10.58 & 3.24 \\
& 38 & 9.55 & 3.56 \\
\hline
\end{tabular}


culty identifying the correct use of terms commonly found in sections of college catalogues.

A closer examination of the results showed that students who planned to attend college scored significantly higher than those who did not plan to attend college (Table 5). The ANOVA yielded an $F$ ratio of 14.04, significant at the .0002 level. Likewise, scores for students whose parents had attended college are significantly higher than it is for students whose parents had not attended college (Table 5). This ANOVA had an $F$ ratio of 8.86 , significant at the .003 level. Students who desired to attend different types of institutions also differed significantly on their CTQ scores (Table 5). Examination of the post hoc comparisons indicated that students who had not yet decided on the type of institution they would like to attend scored significantly lower than students who had cited some preference. Students who planned to attend a liberal arts college scored significantly higher than those that indicated any other preference or no preference. Respondents with brothers or sisters àlready in college and respondents without did not differ significantly in their quiz scores from those with no siblings attending college.

\section{DISCUSSION}

The results of this study indicate that college catalogues are written at a reading difficulty level well above that of the major intended audience-the high school senior. This is not surprising, because the individuals who write college catalogues are college graduates. Yet this poses a problem for the prospective student; even if the catalogue provides sufficient and accurate information, the student is likely to have considerable difficulty understanding it. The problem is further complicated since many college-bound high school students read below their grade level (National Assessment of Educational Progress, 1975; 1976). Colleges that actively seek to attract students through their recruitment literature may find that even a twelfth-grade reading level is too high for the intended audience.

In addition to the reading difficulties discovered in the recruitment literature, students are often unfamiliar with the meaning of the special vocabulary used by those who write admissions materials. The college-bound high-school seniors in this study did not understand many of the terms used in describing admissions procedures, academic program opportunities, and financial aid. Moreover, these terms were not defined in the catalogues, and no glossary was provided. Many of the terms, such as "credit-hour," might not appear in a standard dictionary because they have special meaning within the college context. 


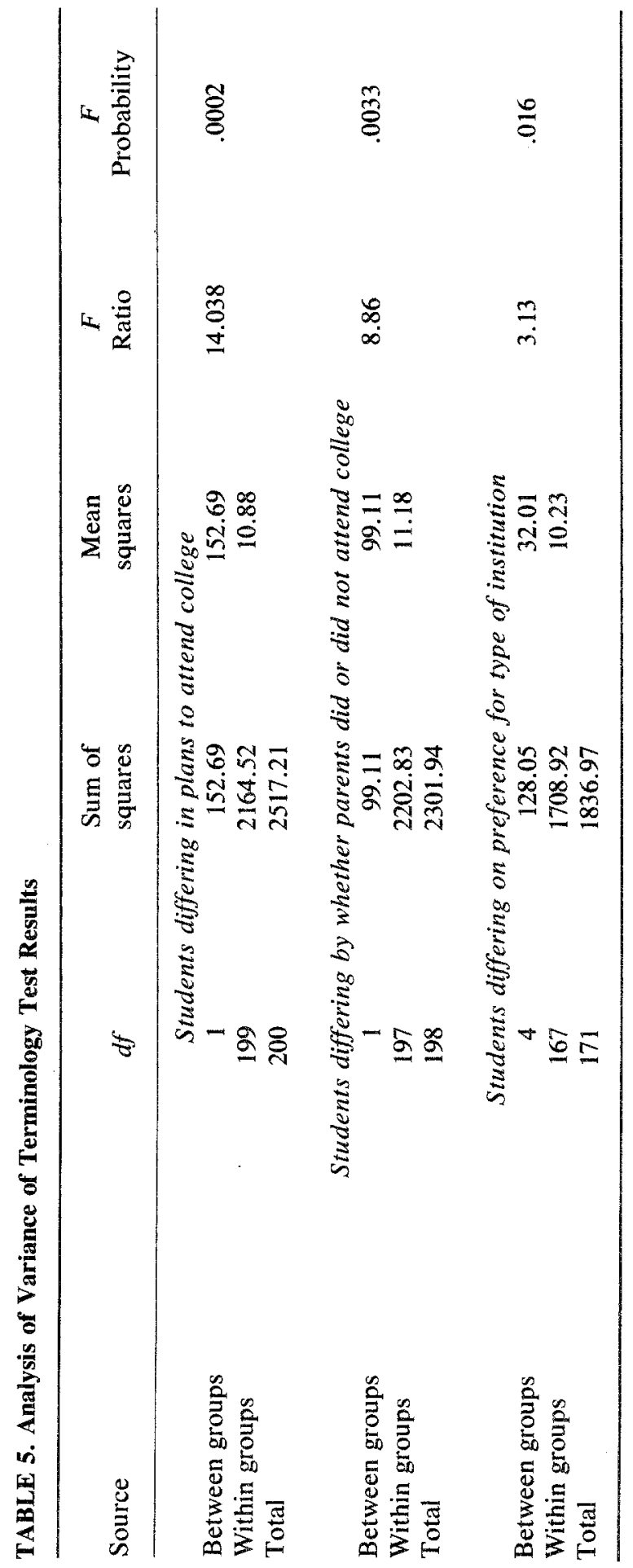


It is not surprising that students whose parents have attended college are more familiar with admissions terminology than students whose parents did not attend college. However it is interesting that having brothers or sisters in college did not seem to affect student scores. Perhaps the lack of effect is because the siblings are usually not at home when the high school senior is choosing a college. Another possibility is that siblings share the same confusion about the terms. Indeed, one earlier study has indicated that college students, even in the middle of their freshman year, do not understand much of the vocabulary used to describe college policies (Chapman and Johnson, 1979). Respondents who expect to attend four-year private colleges seemed to have the best grasp of the terminology. Perhaps students headed toward private liberal arts colleges engage in a broader college search and, in doing so, become more familiar with the vocabulary. Another possibility is that these students, as a group, are different in other characteristics, such as verbal ability, which would account for the difference.

A reasonable question to ask is "Does it matter if the catalogue is difficult reading (or if students do not know what matriculation or credit-hour means)?"' It probably does matter in two ways: first, as high school enrollments drop over the next two decades, competition among colleges for students will increase. It is likely that those colleges that provide straightforward and readable informational material to prospective students will be able to state their case more effectively.

Second, a student's decision about which college to attend is only as good as the information on which it was based. Catalogues are only one of many sources of information. There is evidence, however, that many students do read at least parts of the catalogue (Chapman and Johnson, 1979). It is incumbent upon colleges to provide information that is complete and accurate. Yet, even if the recruitment literature is accurate, the message may be misunderstood if it is written at a level and in a vocabulary too difficult to understand. Results of this study suggest that colleges need to examine their recruitment literature for its level of presentation, as well as for its content.

\section{ACKNOWLEDGMENTS}

The preparation of this article was supported in part by a contract from the Fund for the Improvement of Postsecondary Education, \#G007804724. The opinions expressed in this article do not necessarily reflect those of the sponsor. 


\section{REFERENCES}

Carnegie Commission on Higher Education, A classification of institutions of higher education, Berkeley: Carnegie Commission on Higher Education, 1973.

Chapman, D. Improving information for student choice: the national effort. National ACAC Journal, 1979, 23, 25-26.

Chapman, D., and Johnson, R. Influences in students choice of college: a case study. Ann Arbor: Center for Helping Organizations Improve Choice in Education, School of Education, The University of Michigan, 1979.

Flesch, R. How to test readability. New York: Harper, 1951.

Gilliland, J. Readability. London: The University of London Press, Ltd, 1972.

Gray, W. "A Comparison of Piagetian Theory and Criterion Referenced Measurement," Review of Educational Research, 1978, 48, 2.

Gronlund, N. Preparing Criterion-Referenced Tests for Classroom Instruction, New York: Macmillan, 1973.

Klare, G. R., The Measurement of Readability, Iowa: lowa University, 1963.

Millman, J. Passing scores and test lengths for domain-referenced measures, Review of Educational Research, 1973, 43, 2.

National Assessment of Educational Progress. Functional literary-basic reading performance. Denver: National Assessment of Educational Progress, 1976.

National Assessment of Educational Progress, Functional literary-basic reading performance (an assessment of in-school 17-year-olds in 1974). Denver: National Assessment of Educational Progress, 1975.

Smith, J. and King. W. Readability. Ann Arbor: Michigan Learning Modules, School of Education, University of Michigan, 1977.

Stark, J. Inside information: a handbook on better information for student choice. Washington, D.C.: American Association for Higher Education, 1977.

Stark, J. and Terenzini, P. Alternatives to federal leadership in student consumer information. Ann Arbor: Center for Helping Organizations Improve Choice in Education, School of Education, The University of Michigan, 1978 (ERIC No. ED152179). 